\title{
Correction to: Is the clinical lipidomics a potential goldmine?
}

\author{
Linlin Zhang • Xianlin Han $•$ Xiangdong Wang
}

Published online: 29 August 2020

(C) Springer Nature B.V. 2019

\section{Correction to: Cell Biol Toxicol (2018) 34:421-423 \\ https://doi.org/10.1007/s10565-018-9441-1}

The article Is the clinical lipidomics a potential goldmine?, written by Linlin Zhang, Xianlin Han and Xiangdong Wang, was originally published electronically on the publisher's internet portal (currently SpringerLink) on 21 July 2018 with open access. With the author(s)' decision to step back from Open Choice, the copyright of the article changed on August 2019 to (C) Springer Nature B.V. 2019 and the article is forthwith distributed under the terms of copyright.

The original article has been corrected.

Publisher's note Springer Nature remains neutral with regard to jurisdictional claims in published maps and institutional affiliations.

The online version of the original article can be found at https://doi.org/10.1007/s10565-018-9441-1

\section{Zhang $\cdot$ X. Wang $(\bowtie)$}

Zhongshan Hospital Institute of Clinical Science, Shanghai Institute of Clinical Bioinformatics, Fudan University Shanghai Medical School, Shanghai, China

e-mail: xiangdong.wang@ clintransmed.org

X. Han $(\bowtie)$

Barshop Institute for Longevity and Aging Studies, Glenn Biggs Institute for Alzheimer's \& Neurodegenerative Diseases,

Department of Medicine, Division of Diabetes, Department of Biochemistry and Structural Biology, University of Texas Health Science Center at San Antonio, San Antonio, TX, USA e-mail: hanx@uthscsa.edu 